\title{
The nucleocapsid of the hepatitis B virus: a remarkable immunogenic structure
}

\author{
Peter Vanlandschoot, Tinghua Cao ${ }^{1}$, Geert Leroux-Roels* \\ Center for Vaccinology, Department of Clinical Biology, Microbiology and Immunology, \\ Ghent University Hospital, De Pintelaan 185, 9000 Ghent, Belgium
}

\begin{abstract}
The hepatitis B virus nucleocapsid or core antigen is extremely immunogenic during infection and after immunization. This review summarizes several features of the nucleocapsid which explain this exceptionally high immunogenicity: a unique three-dimensional folding, the presence of a region that interacts with immunoglobulins outside the classical antibody-binding site, the presence of many CD4+ T cell epitopes, and the presence of encapsidated nucleic acids. Because of these features, nucleocapsids efficiently interact and activate antigen presenting cells, especially naïve B cells. This leads to the generation of a dominant Th1 immunity phenotype and the secretion of high levels of IgM and IgG anti-nucleocapsid antibodies.
\end{abstract}

(C) 2003 Elsevier B.V. All rights reserved.

Keywords: Hepatitis B virus; Nucleocapsid; B cell; Immunogenicity; RNA

\section{Introduction}

Infections with the hepatitis B virus (HBV) remain a major cause of morbidity and mortality worldwide. More than 2 billion people alive today have been infected by HBV and over 350 million people remain chronically infected. The clinical manifestations of HBV infection are highly polymorphic, ranging from inapparent forms to fulminant hepatitis, acute self-limited hepatitis, chronic hepatitis, cirrhosis, and hepatocellular carcinoma (HCC). HBV is transmitted sexually, parenterally, and from mother to infant in the perinatal period. Most adult onset HBV infections resolve, presumably due to the polyclonal, multi-specific immune responses that the patients mount against the viral proteins. Approximately 5-10\% of acutely infected adults become persistently infected by the virus. However, perinatal HBV infections are rarely cleared in that over $90 \%$ of infected children develop chronic infections.

HBV is the prototype of a family of viruses, referred to as Hepadnaviridae. It is the smallest animal DNA virus known. The genome consists of about 3200 nucleotides and is a partially double-stranded relaxed circular DNA molecule. Four open reading frames-the polymerase $(\mathrm{P})$

\footnotetext{
* Corresponding author. Tel.: +32-9-240-21-23; fax: +32-9-240-63-11.

E-mail address: Geert.Lerouxroels@UGent.be (G. Leroux-Roels).

${ }^{1}$ Present address. Baylor Institute of Immunology Research, 3434 Live Oak Street, Dallas, TX 75204, USA
}

gene, the $\mathrm{X}$ gene, the precore/core (preC/C) gene, and the surface (preS/S) gene-have been identified which encode seven proteins. Four major viral RNA molecules are found in infected cells. The pregenomic RNA, which serves as the template for viral DNA formation, additionally serves as the mRNA for the viral polymerase $(\mathrm{P})$ and the core proteins ( $\mathrm{HBcAg}$ and $\mathrm{HBeAg}$ ). The preS/L-mRNA is the template for the translation of the membrane proteins $\mathrm{M}$ and $\mathrm{L}$, which have 226 carboxy-terminal amino acids in common with the $\mathrm{S}$ protein. This membrane protein is translated from the S-mRNA. From the X-mRNA, the $\mathrm{X}$ protein is translated. The $\mathrm{P}$ protein, $\mathrm{HBcAg}$ and the membrane proteins $\mathrm{S}, \mathrm{M}$, and $\mathrm{L}$ are structural proteins. $\mathrm{HBcAg}$ monomers assemble into a capsid structure, which encapsidates pregenomic RNA together with the P protein. This pregenomic RNA is reverse transcribed into DNA, an event that occurs within the infected cell. These nucleocapsids interact with cytosolically exposed regions of the $\mathrm{L}$ protein present in the endoplasmic reticulum-to-Golgi intermediate compartment, into which viruses bud (Seeger and Mason, 2000). Besides infectious virions, also called Dane particles, infected hepatocytes produce nucleocapsid-free particles, termed HBsAg. These can accumulate to several hundred micrograms per milliliter in the blood. The function of these particles is unclear (Vanlandschoot and Leroux-Roels, 2003). A second secreted monomeric viral protein is $\mathrm{HBeAg}$. Mature $\mathrm{HBeAg}$ is a $16 \mathrm{kDa}$ secreted, processed, and non-particulate form of $\mathrm{HBcAg}$ that is truncated at the $\mathrm{C}$-terminus at amino 
acid position 149 (Takahashi et al., 1983) while it retains an additional 10 precore amino acids at its $\mathrm{N}$-terminus (Standring et al., 1988). As for HBsAg, the role during infection of $\mathrm{HBeAg}$ and the $\mathrm{X}$ protein remains largely unclear (Milich et al., 1990; Staib et al., 2003). Recently, two novel proteins were reported, which are translated from alternatively spliced RNAs (Soussan et al., 2000; Huang et al., 2000).

During HBV infection, at least four antigen-antibody systems are observed: (1) HBsAg and anti-HBsAg; (2) preS antigen and anti-preS antibody; (3) $\mathrm{HBcAg}$ and anti-HBcAg; and (4) $\mathrm{HBeAg}$ and anti-HBeAg. These serological markers are used to demonstrate HBV infection and to discriminate acutely from chronically infected patients. The appearance of the anti-envelope antibody in the naturally infected subject, although it is often delayed, indicates the elimination of virus and recovery. Usually, anti-HBsAg is readily detectable in the patients who successfully clear the virus, but not in the chronic patients. Seroconversion from $\mathrm{HBeAg}$ to anti-HBeAg occurs later in the course of the infection and its appearance usually correlates with elimination of virus.

Remarkably, HBcAg seems significantly more immunogenic than the envelope proteins and $\mathrm{HBeAg}$. High titers of anti-HBcAg are produced by virtually all HBV-infected patients. IgM anti-HBcAg appears early in acute hepatitis $\mathrm{B}$, and $\mathrm{IgG}$ anti-HBcAg can persist with slowly decreasing titers for many years, and even for life. Many studies have shown that during chronic HBV infection, the titer of IgM anti-HBcAg may fluctuate considerably in relation to clinical reactivation and may be useful to monitor antiviral therapy (Sjogren and Hoofnagle, 1985; Surrenti et al., 1986; Gerlich et al., 1986; Koike et al., 1987; Smith et al., 1992; Colloredo Mels et al., 1993; Brunetto et al., 1993). The presence of IgM anti-HBcAg correlated with persistent viral replication and could generally be used as an indicator for acute exacerbation in chronic patients. The significance of $\mathrm{IgM}$ anti-HBcAg has been further clarified by Marinos et al. (1994), who showed that serum IgM anti-HBcAg strongly correlated with hepatocellular damage immunopathologically related to HBV infection in patients. This study also showed that the IgM anti-HBcAg index value also correlated well with the degree of hepatocellular lysis (AST) but not with HBV replication (HBV-DNA).

$\mathrm{HBcAg}$ and $\mathrm{HBeAg}$ share most of their sequence (149 amino acid homology) and are highly cross-reactive at the $\mathrm{T}$ cell level (Milich et al., 1987, 1988). Nevertheless, HBcAg and $\mathrm{HBeAg}$ are recognized differently by $\mathrm{B}$ cells and the immune response towards both antigens appears to be regulated independently. This observation has raised a lot of interest and extensive research suggests that this higher immunogenicity of $\mathrm{HBcAg}$ is a consequence of several characteristics: a unique three-dimensional folding, the presence of a region that interacts with immunoglobulins outside the classical antibody-binding site, the presence of many CD4+ T cell epitopes, and the presence of encapsidated nucleic acids.

\section{Structural characteristics of the capsid protein HBcAg}

The nucleotide sequence of the HBV core protein encodes a single polypeptide of 183 amino acids $(21 \mathrm{kDa})$ that assembles to form nucleocapsid particles. The nucleocapsid of HBV is a $30-32 \mathrm{~nm}$ particle. The $\mathrm{HBcAg}$ protein of HBV consists of two domains: the assembly domain (amino acids (aa) 1-149) that forms the contiguous spherical shell, and the protamine domain (aa 150-183) that is responsible for RNA packaging (Petit and Pillot, 1985; Nassal, 1992). When the protamine domain is removed, the core protein still assembles into shells and is practically indistinguishable from full-length capsid particles using electron cryomicroscopy, provided the truncation point is not before amino acid 140. However, it no longer packages nucleic acid (Gallina et al., 1989; Birnbaum and Nassal, 1990). Previous study (Wingfield et al., 1995) on the secondary structure of HBV capsid protein with far-UV circular dichroism (CD) indicated that $\mathrm{HBcAg}$ is predominantly (43-60\%) $\alpha$-helical and has a low content of $\beta$-sheet. Recently, X-ray and electron cryomicroscopy studies (Conway et al., 1997; Bottcher et al., 1997; Wynne et al., 1999) (see Fig. 1) have further shown that the structure of HBV capsid protein is largely $\alpha$-helical, and dominated by a long $\alpha$-helical hairpin consisting of residues 50-73 ( $\alpha 3)$ and $79-110(\alpha 4)$. The N-terminal region (aa 1-12) adopts an irregular structure, followed by a short helix, $\alpha 1$ (aa 13-17), and a long helix, $\alpha 2$ (aa 27-43), which together surround three sides of the $\alpha$-helical hairpin. The C-terminal region consists of $\alpha 5$ (aa 112-127) followed by an irregular proline-rich loop (aa 128-136) and an extended strand (aa 137-143). The conserved hydrophobic core is responsible for the stabilization of the monomer fold.

Two monomers of HBV polypeptide associate to form a compact dimer by homologous intermolecular disulfide bridges (Bottcher et al., 1997; Wynne et al., 1999). HBcAg contains four cysteine residues at positions $48,61,107$, and 183. Studies (Zheng et al., 1992; Nassal et al., 1992) using site-directed cysteine mutation showed that all mutants assemble into essentially identical core particle structures, suggesting that disulfide bonds are not essential for core particle formation. Indeed, disulfide bridges are not found in intracellular capsids and the extracellular formation of the disulfide bridges can be enhanced by $\mathrm{Cu}^{2+}$ (Nassal et al., 1992). No intra-chain disulfide bonds occur. Cys61, located at the dimer interface, is always and Cys48 is partly involved in inter-chain disulfide bonds with identical residues of another monomer. Cys107 is a free thiol buried within the particle structure, whereas Cys 183 is always involved in a disulfide bond with the Cys 183 of the partner monomer.

$\mathrm{HBcAg}$ proteins are able to assemble into two particle sizes, large $(34 \mathrm{~nm})$ and small $(30 \mathrm{~nm})$, composed of 240 and 180 subunits, which corresponded to triangulation number $T=4$ and $T=3$ dimer clustered packings. The subunits are clustered as dimers (120 or 90), producing the spikes 

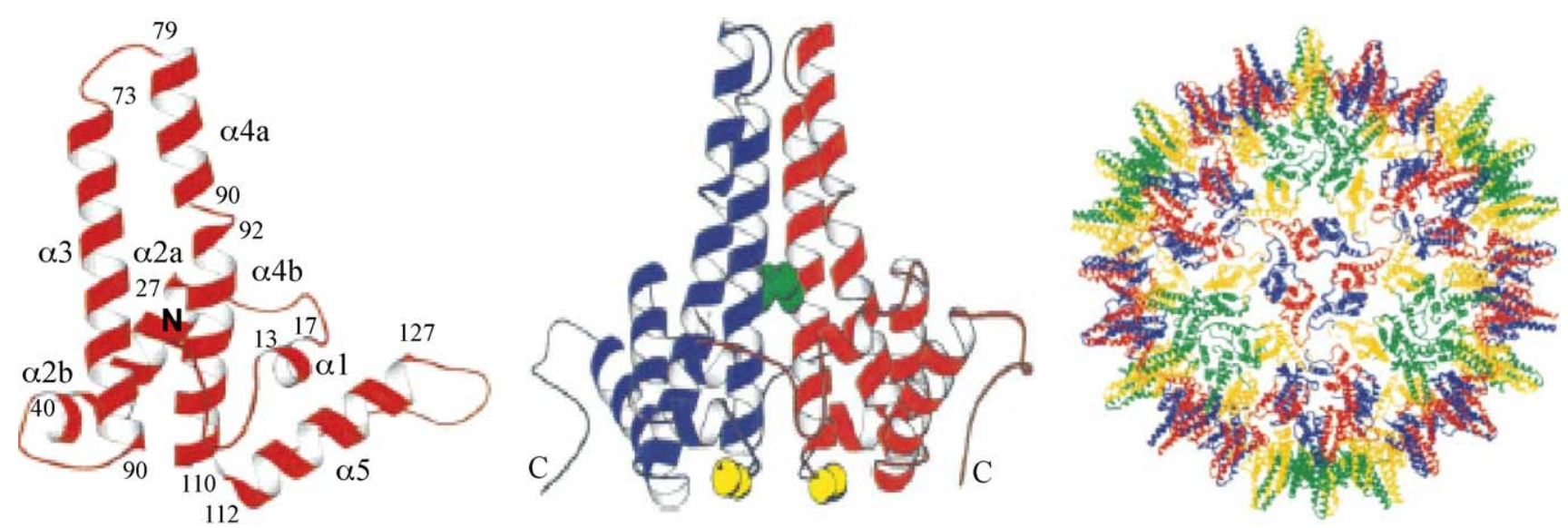

Fig. 1. Structure of the HBV capsid monomer derived from the crystal structure (left), the capsid dimer (middle), and the capsid (right). Source: Wynne et al., 1999.

that stick out from the underlying shell domain. The dimer clustering of subunits produces spikes on the surface of the shell, which consist of radial bundles of four long $\alpha$-helices (Bottcher et al., 1997; Conway et al., 1997). Each HBcAg monomer participates in helical bundle formation by an antiparallel $\alpha$-helical hairpin about $42 \AA$ in length. Most of the monomer-monomer interface within the dimer consists of interactions between the two homologous straight $\alpha$-helices in the two opposed hairpins (Bottcher et al., 1997; Conway et al., 1997). The capsid is fenestrated, with large pores with a diameter of $12-15 \AA$. It has been proposed that these pores are essential to allow nucleotides access to the capsid interior during the DNA synthesis and it is also relevant to the reported accessibility of the C-terminal tail to proteinases and antibodies (Machida et al., 1991; Wynne et al., 1999). When the C-terminal region is replaced by foreign inserted sequences, these insertions can be detected by special antibodies on the outside of the assembled capsids (Borisova et al., 1989).

\section{The immunogenic structure of $\mathrm{HBcAg}$}

\subsection{Human $\mathrm{CD} 4+\mathrm{T}$ cell recognition sites}

$\mathrm{HBcAg}$ contains numerous $\mathrm{T}$ cell recognition sites. In one study (Ferrari et al., 1991), where a series of synthetic peptides covering the $\mathrm{HBcAg}$ molecule was used to analyze the $\mathrm{T}$ cell recognition of $\mathrm{HBcAg}$, amino acid sequence (aa 50-69) was found to be the dominant $\mathrm{T}$ cell epitope in man. A significant proportion of $\mathrm{T}$ cells from different $\mathrm{HBV}$ patients was also able to respond to two additional peptides corresponding to amino acids 1-20 and 117-131 of the HBcAg (Ferrari et al., 1991). Another group revealed additional predominant $\mathrm{T}$ cell recognition sites within $\mathrm{HBcAg}$ molecule, namely amino acids $1-25$ and amino acids $61-85$ (Jung et al., 1995). Importantly, two immunodominant $\mathrm{T}$ cell epitopes (aa 1-20 and 50-69 or 1-25 and 61-85) within
$\mathrm{HBcAg}$ were found to induce significant $\mathrm{T}$ cell responses in a large proportion of patients (Ferrari et al., 1991; Jung et al., 1995) irrespectively of their HLA haplotype. In addition to these major epitopes, minor $\mathrm{T}$ cell epitopes within $\mathrm{HBcAg}$ have been identified, such as amino acids 20-34, 28-47, 70-89, 82-101, 100-119, 140-155, and 169-183 (Ferrari et al., 1991; Cao et al., 2002).

$\mathrm{HBcAg}$-specific $\mathrm{T}$ cells from a variety of inbred mouse strains recognize multiple but distinct sites within the $\mathrm{HBcAg} / \mathrm{HBeAg}$ sequences. Each mouse strain recognizes a predominant $\mathrm{T}$ cell determinant and the specificity of this recognition is dependent on the H-2 haplotype of the responding strain (Milich et al., 1987).

\subsection{Human $C D 8+T$ cell recognition sites}

So far, only one HLA-A2-restricted epitope (aa 18-27) has been identified in the $\mathrm{HBcAg} / \mathrm{HBeAg}$, whereas more CTL sites within envelope and polymerase proteins were found. Additional CTL nucleocapsid epitopes located at HBcAg residues (aa 141-151) were defined (Missale et al., 1993). The CTL response to this epitope is dually restricted by the HLA-A31 and HLA-Aw68 alleles. Another naturally processed $\mathrm{HBcAg}$ peptide (aa 88-96) was identified and recognized by HLA-A11-restricted CD8+ CTLs (Tsai et al., 1996).

\subsection{B cell recognition sites}

The analysis of B cell recognition sites within core particle has revealed, so far, only one major conformational antigenic determinant which was located around amino acid position 80 (aa 74-83) (Salfeld et al., 1989). Another B cell epitope located around portion (aa 107-118) has been reported by others (Colucci et al., 1988). The dependence of $\mathrm{HBcAg}$ antigenicity on conformational integrity suggests that linear peptides may not be sufficient to mimic $\mathrm{HBcAg}$ $\mathrm{B}$ cell epitopes completely. This is strongly supported by re- 
cent findings on the structure of core particle. The sequence 78-82 corresponding to the immunodominant region of the core protein lies at the tip of the spike. Recently, using cryomicroscopy and a monoclonal antibody that recognizes the peptide from residues 78 to 83, Conway et al. (1998) have shown that this epitope (78-83) resides on the outer rim of the $30 \AA$ long spikes. In addition to the major immunodominant region, another epitope in the region of amino acid 130 has been identified (Salfeld et al., 1989). This region lies at the end of the C-terminal helix, forming a loop that is exposed and makes a small protrusion on the surface of the shell. This protrusion provides the next most exposed and accessible feature on the surface. The monoclonal antibodies against this region (aa 127-133) label well-preserved shells (Pushko et al., 1994).

\section{The immunogenicity of capsids in mice and man}

In 1986, Milich and McLachlan reported that the nucleocapsid is both a $\mathrm{T}$ cell-independent and a $\mathrm{T}$ cell-dependent antigen. In euthymic mice, a single injection of capsids stimulated IgM and IgG antibodies and helper T cell function. When capsids were injected into athymic (nude) mice, which do not have T cells, capsids still induced IgM and IgG class antibodies. This $\mathrm{T}$ cell-independent induction of antibodies was lost when capsids were denatured. Nevertheless, both intact and denatured capsids were highly cross-reactive at the $\mathrm{T}$ cell level. Following these observations, capsids proved more immunogenic in terms of antibody production as compared to $\mathrm{HBeAg}$. Again capsids and $\mathrm{HBeAg}$ were equally immunogenic and cross-reactive at the T cell level (Milich et al., 1988). These experiments were performed using Freund's complete or incomplete adjuvant, but capsids turned out to be very immunogenic even in the absence of adjuvant. Immunizations with as little as $6 \mathrm{ng}$ of capsids in saline resulted in detectable anti-HBcAg production 2 weeks after a single injection. Furthermore, capsids elicited primarily $\operatorname{IgG} 2 \mathrm{a}$ and $\mathrm{IgG} 2 \mathrm{~b}$ antibodies, with low level of IgG3 and no IgG1 antibodies. Such a response is indicative for a dominant Th1-like phenotype. In contrast, $\mathrm{HBeAg}$ which is highly cross-reactive at the $\mathrm{T}$ cell level induced primarily IgG1 antibodies, indicative for a Th2-like phenotype. Cytokine production by capsid and HBeAg-primed Th cells confirmed this Th1 or Th2 phenotype: capsid-primed $\mathrm{T}$ cells efficiently produced IL-2 and IFN- $\gamma$ but low levels of Il-4. HBeAg-primed T cells efficiently produced Il-4 and low levels of IFN- $\gamma$. The use of incomplete Freund's adjuvant increased the antibody response, but did not alter the IgG isotype profile. In athymic mice, the $\mathrm{T}$ cell-independent anti-capsid response was characterized by efficient $\operatorname{IgG} 2 \mathrm{~b}$ and $\mathrm{IgG} 3$ isotype production and virtually no IgG1 and IgG2a (Milich and McLachlan, 1986; Milich et al., 1997b).

From these and additional experiments, it was concluded that the structural form of the capsids was the determin- ing factor in the outcome of Th phenotype. Moreover, the structure of the capsids was considered to be directly responsible for the $\mathrm{T}$ cell-independent induction of $\operatorname{IgM}$ and IgG in mice and more importantly during $\mathrm{HBV}$ infection in humans. However, all the evidences for the unique quality of capsids was generated in mice, which is not a natural host of HBV. Because experiments with humans are limited and in order to examine the immunogenicity of capsids for human lymphoid cells, a human peripheral blood leukocyte (hu-PBL)-NOD/severe combined immunodeficient (Scid) mouse model was developed. The ability of Scid mice to accept xenografts has been utilized in different research fields as a laboratory model to study the human immune system (Mosier, 1991; Tary-Lehmann et al., 1995). In most models, hu-PBL were injected into the peritoneal cavities of recipient mice, leading to a rapid and predominant expansion of $\mathrm{T}$ cells. Recently, we discovered that transfer of hu-PBL directly into the spleens of NOD/Scid mice, irradiated and treated with an antibody that reduces mouse natural killer cells, led to a vigorous expansion of B cells and their differentiation into plasmacytoid cells (Depraetere et al., 2001). Using this model, we showed that HBV capsids induced the production of capsid-binding IgM molecules when PBL of unprimed individuals together with capsids were transferred into NOD/Scid recipient mice. This was observed with adult human and neonatal (cord blood) donors. In addition, capsids activated purified human B cells to produce IgM anti-capsid in the chimeric mice, thus providing evidence that capsids behave as a $\mathrm{T}$ cell-independent antigen in humans. However, a switch from IgM to IgG production could not be induced, not even after a booster injection with capsids in vivo. However, capsid-specific IgG was readily detected when PBL were used from subjects who had recovered from an acute HBV infection or who still had an ongoing chronic HBV infection. From these observations, it was concluded that the nucleocapsid is both a $\mathrm{T}$ cell-independent and a $\mathrm{T}$ cell-dependent antigen in humans as in mice (Cao et al., 2001).

\section{What determines this high immunogenicity of the capsid?}

Milich and McLachlan in 1986 hypothesized that a unique structural folding of the capsid was the underlying determinant for its high immunogenicity. They further suggested that capsids were able to directly activate B cells to produce antibodies to the core in the presence or absence of $\mathrm{HBcAg}$ - or HBeAg-sensitized T cells. When the structure of the capsid was revealed by electron cryomicroscopy it was proposed that the orientation of the dimeric spikes distributed over the surface of the capsid shell might be optimal for cross-linking B cell membrane Ig antigen receptors. The position of the dominant $\mathrm{B}$ cell epitope on the tip of the spikes was very provocative in this respect. Based on this 
hypothesis, Milich et al. (1997) showed that spleen cells from naïve mice were able to activate $\mathrm{HBcAg}$-specific $\mathrm{T}$ cell hybridomas very efficiently when using capsids but not with $\mathrm{HBeAg}$. Depletion of the B cells abolished this capacity of capsids to efficiently activate the $\mathrm{HBcAg}$-specific $\mathrm{T}$ cell hybridomas. In contrast, purified B cells preferentially presented capsids as compared with $\mathrm{HBeAg}$. The role of $\mathrm{B}$ cells in the activation of HBcAg-specific T cell hybridomas was further substantiated using spleen cells from B cell negative "knockout" ( $\mu \mathrm{MT}$ ) mice. Antibodies directed against mouse Ig significantly inhibited B cell presentation of capsids and not of a HBcAg-derived peptide to T cell hybridomas. Similarly, capsid-specific antibodies inhibited B cell presentation of capsids. These observations demonstrated that only capsid-specific B cells function as antigen presenting cells and that capsids do not behave like superantigens. Capsids were capable of inducing the co-stimulatory molecules CD80 and CD86 on purified resting B cells. Since similar results were obtained using resting $\mathrm{B}$ cells from LPS-non-responsive $\mathrm{C} 3 \mathrm{H} / \mathrm{HeJ}$ mice, it is very unlikely that the immunostimulatory qualities of the capsids were due to possible endotoxin contaminants. Naïve B cells produced capsid-binding IgM, when co-cultured with very low levels of capsids and $\mathrm{T}$ cells from $\mathrm{HBcAg}$ - or $\mathrm{HBeAg}$-specific $\mathrm{T}$ cell receptor transgenic mice (Lazdina et al., 2001). Finally, it was demonstrated that B cells can function as antigen presenting cells in mice (Milich et al., 1997). Using three different methods to quantify capsid-binding B cells, their frequency in the spleen of naïve mice was estimated to be in the range of $4-8 \%$ (Lazdina et al., 2001).

Based on these observations, it was predicted that naïve B cells that bind and present HBV capsids have Ig surface receptors with a common motif or a restricted usage of variable heavy (VH) and light chain (VL) coding genes. Cloning and sequencing of the $\mathrm{VH}$ and $\mathrm{VL}$ domains of seven IgM secreting hybridomas revealed that six were related to human and murine VH1 germ line gene families; one was related to the murine VH3 family. A linear motif that binds $\mathrm{HBcAg}$ was identified in the framework region 1-complementarity-determining region 1 (FR1-CDR1) junction of these genes. This motif was either present in heavy chains of the mouse VH1 family or in the light chain of the mouse VH3 family. Peptides, homologous to the FR1-CDR1 junctions of human VH1 and VH7 germ lines were shown to bind to $\mathrm{HBcAg}$ (Lazdina et al., 2001). The binding site on the capsids was subsequently shown to involve residues 76-80, which lie on the tip of the spikes and are part of the immunodominant epitope (Lazdina et al., 2003).

From these observations it is very clear that the high humoral immunogenicity of HBV capsids is determined by its capacity to interact with B cells. However, it remains unclear why this interaction would skew the immune response towards a Th1 phenotype. Oligonucleotides (ODN) with immunostimulating sequences are potent activators of the innate and adaptive immune system. Mixed with protein they prime a Th1 immunity and CTL activity (18-26). Capsids expressed in bacteria, yeast, or mammalian cells and made of full-length core proteins always contain RNA, approximately 5-20 ng/ug varying in length from 30 to 3000 nucleotides (Birnbaum and Nassal, 1990). Based on these observations, Schirmbeck and colleagues investigated if the encapsidated RNA was critical for Th1 priming. Deletion of the C-terminal arginine-rich end generates capsids in which $>98 \%$ of RNA binding is lost. Immunization of mice with such truncated capsids no longer primed a Th1 immune response, but a clear Th2 response. Immunization of mice with full-length capsids induced primarily $\operatorname{IgG} 2 \mathrm{a}$ isotype antibodies and secretion of high levels of IFN- $\gamma$ by CD4+ T cells, while primarily IgG1 and low levels of IFN- $\gamma$ were observed when using truncated capsids. Interestingly, non-immune cells and bone marrow-derived dendritic cells stimulated with full-length capsids produced IL-12 p70. Capsids treated with SDS, which results in loss of encapsidated RNA, no longer induced this Th1 phenotype, indicating that the low amounts of RNA in the capsids are required for priming Th1 immunity. Codelivery of RNA with $\mathrm{HBeAg}$ resulted in a more Th1 biased immunity instead of a Th2 immune response. However, 1000-fold higher doses of RNA had to be used compared to the small amounts of RNA associated with full-length capsids. Intradermal delivery with the gene gun always primes a Th2 immune response. Interestingly, using this gene gun it was demonstrated that intradermal immunization of mice with full-length capsids, resulted in a mixed Th1/Th2 immunity. Gene gun immunization with truncated capsids resulted in a clear Th2 immunity (Riedl et al., 2002).

Based on these observations, Schirmbeck and colleagues suggested that trace amounts of prokaryotic or eukaryotic RNA have a potent enhancing and modulating effect on the immune response towards the capsids. They proposed that the particle-associated delivery is a key factor for this adjuvant effect of the RNA. The RNA is protected from degradation by nucleases during its extracellular phase and during uptake by cells. Following uptake of capsids by endocytosis or macropinocytosis, particles would be disrupted in an acid late endosomal or early lysosomal compartment. Uptake of one capsid delivers 180-240 copies of a single protein into the antigen-processing and -presenting cell. In the same compartment the encapsidated RNA would probably be released, allowing it to interact with immunostimulatory receptors. For immune stimulating ODN it has indeed been demonstrated that their adjuvant effect requires the uptake into an acidic compartment (Yi et al., 1998; Hemmi et al., 2000), where they bind to toll-like receptor 9, triggering signal transduction by MyD88, MAP kinases, and $\mathrm{NF} \kappa \mathrm{B}$. Toll-like receptor 3 has been demonstrated to bind double-stranded RNA and to activate MyD88, MAP kinases, and NFKB (Alexopoulou et al., 2001; Matsumoto et al., 2002). A similar interaction of capsid-derived RNA with toll-like receptor 3 in endosomes could explain the intrinsic adjuvant effect of HBV capsids (see Fig. 2) 


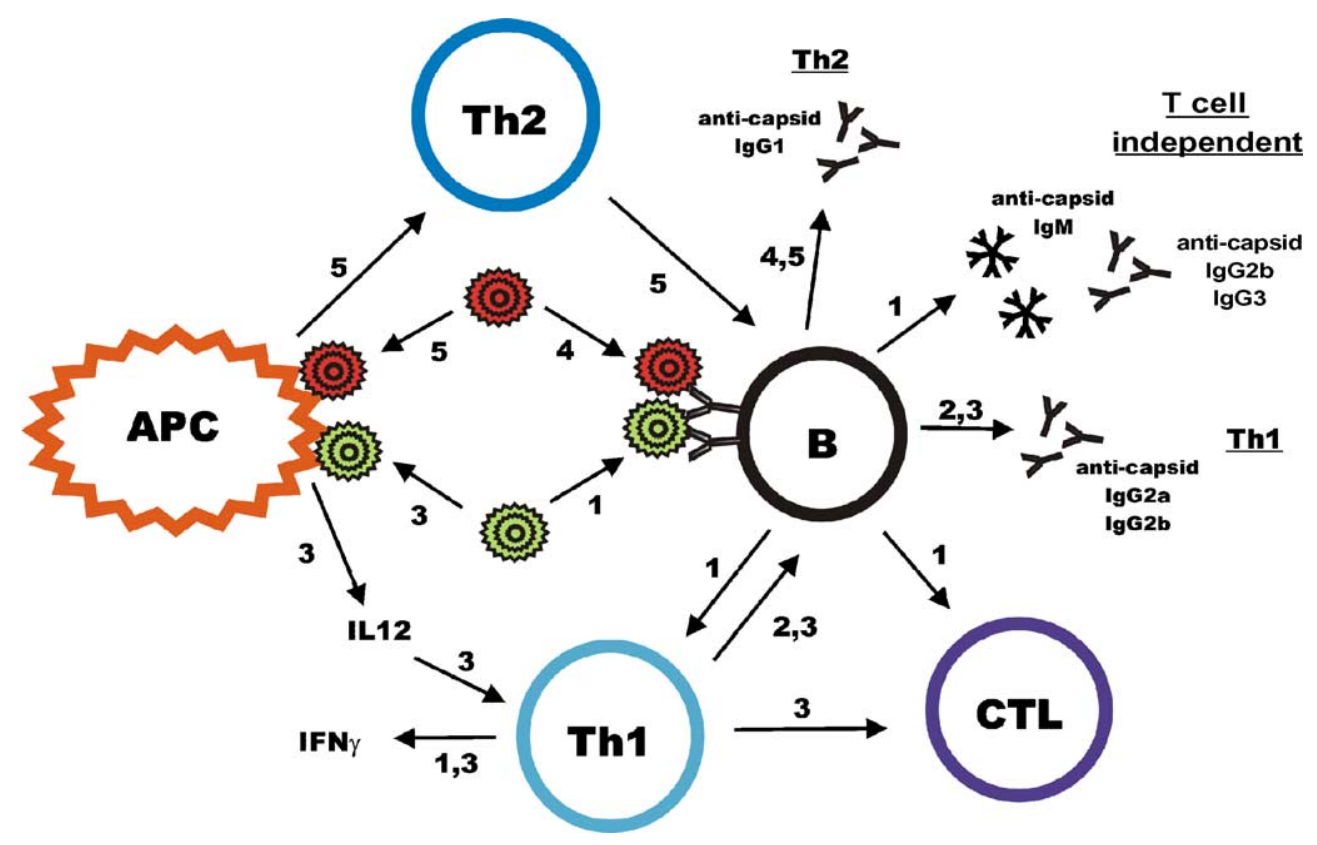

Fig. 2. Schematic representation of the proposed different immune response pathways triggered by the HBV nucleocapsid. Pathway 1 (T cell-independent pathway): Binding of RNA-containing nucleocapsids (green) leads to T cell-independent secretion of $\operatorname{IgM}, \operatorname{IgG} 2 \mathrm{~b} / 3$, and in the induction of Th1 cells and CTLs. Pathway 2: Following binding and uptake of nucleocapsids by naïve B cells, the interaction between these B cells and T cells results in the T cell-dependent secretion of IgG2a and IgG2b. Pathway 3: The uptake of RNA-containing nucleocapsids leads to activation of antigen presenting cells (dendritic cells), secretion of IL-12, and generation of Th1 cells. These enhance the secretion of IgG2a and IgG2b isotype antibodies. Pathways 4 and 5: Binding of truncated capsids, denatured capsids or $\mathrm{HBeAg}$ (red) to B cells, together with uptake by antigen presenting cells, results in induction of Th2 cells and secretion of IgG1 isotype antibodies.

\section{Concluding remarks}

Crucial for the exceptional high humoral and Th1 immunogenicity of the HBV nucleocapsid is the presence in its primary sequence of potent $\mathrm{T}$ helper epitopes, the proper spacing between the repetitive tips and the presence of encapsidated RNA. The ability of capsids to bind and activate a high frequency of naïve $B$ cells is probably mediated through binding of the tip of the repetitive spikes to a linear motif present in the FR1-CDR1 junction of the heavy and light chain of surface immunoglobulins. Following binding, the cross-linking of Ig membrane receptors results in intracellular signaling, secretion of $\operatorname{IgM}$ and $\mathrm{IgG}$ anti-HBcAg, and upregulation of co-stimulatory molecules. Capsids are taken up and capsid-derived $\mathrm{T}$ cell epitopes, which are abundant in the core protein, are presented to naïve $\mathrm{T}$ helper cells. The interaction between the activated $\mathrm{B}$ cells and $\mathrm{T}$ cells subsequently is thought to result in the development of a Th1 helper phenotype, followed by enhanced antibody isotype switching and increased production of $\mathrm{IgG}$ anti- $\mathrm{HBcAg}$ antibodies. It was suggested recently that B cells that bind capsids can prime cytotoxic $\mathrm{T}$ cells as well (Lazdina et al., 2003). Finally, antigen presenting cells, other than B cells, probably help to drive the response towards a Th1 phenotype in euthymic mice. Non-specific uptake of capsids through endocytosis or macropinocytosis releases the encapsidated RNA. This results in a strong activation of the cells and production of IL-12, a well-known strong inducer of Th1 immunity.

\section{References}

Alexopoulou, L., Holt, A.C., Medzhitov, R., Flavell, R.A., 2001. Recognition of double-stranded RNA and activation of NF-kappaB by Toll-like receptor 3. Nature 413, 732-738.

Birnbaum, F., Nassal, M., 1990. Hepatitis B virus nucleocapsid assembly: primary structure requirements in the core protein. J. Virol. 64, 33193330.

Borisova, G.P., Berzins, I., Pushko, P.M., Pumpen, P., Gren, E.J., Tsibinogin, V.V., Loseva, V., Ose, V., Ulrich, R., Siakkou, H., Rosenthal, H.A., 1989. Recombinant core particles of hepatitis B virus exposing foreign antigenic determinants on their surface. FEBS Lett. 259, 121-124.

Bottcher, B., Wynne, S.A., Crowther, R.A., 1997. Determination of the fold of the core protein of hepatitis B virus by electron cryomicroscopy. Nature 386, 88-91.

Brunetto, M.R., Cerenzia, M.T., Oliveri, F., Piantino, P., Randone, A., Calvo, P.L., Manzini, P., Rocca, G., Galli, C., Bonino, F., 1993. Monitoring the natural course and response to therapy of chronic hepatitis B with an automated semi-quantitative assay for IgM anti-HBc. J. Hepatol. 19, 431-436.

Cao, T., Lazdina, U., Desombere, I., Vanlandschoot, P., Milich, D.R., Sallberg, M., Leroux-Roels, G., 2001. The hepatitis B virus core antigen binds and activates naïve human $\mathrm{b}$ cells in vivo studies in a human PBL-NOD/SCID mouse model. J. Virol. 75, 6359-6366.

Cao, T., Desombere, I., Vanlandschoot, P., Sallberg, M., Leroux-Roels, G., 2002. Characterization of HLA DR13-restricted CD4(+) T cell epitopes of hepatitis B core antigen associated with self-limited, acute hepatitis B. J. Gen. Virol. 83, 3023-3033. 
Colloredo Mels, G., Bellati, G., Leandro, G., Brunetto, M.R., Vicari, O., Piantino, P., Borzio, M., Angeli, G., Ideo, G., Bonino, F., 1993. Role of IgM antibody to hepatitis B core antigen in the diagnosis of hepatitis B exacerbations. Arch. Virol. Suppl. 8, 203-211.

Colucci, G., Beazer, Y., Cantaluppi, C., Tackney, C., 1988. Identification of a major hepatitis B core antigen ( $\mathrm{HBcAg}$ ) determinant by using synthetic peptides and monoclonal antibodies. J. Immunol. 141, 43764380.

Conway, J.F., Cheng, N., Zlotnick, A., Wingfield, P.T., Stahl, S.J., Steven, A.C., 1997. Visualization of a 4-helix bundle in the hepatitis B virus capsid by cryo-electron microscopy. Nature 386, 91-94.

Conway, J.F., Cheng, N., Zlotnick, A., Stahl, S.J., Wingfield, P.T., Belnap, D.M., Kanngiesser, U., Noah, M., Steven, A.C., 1998. Hepatitis B virus capsid: localization of the putative immunodominant loop (residues 78 to 83 ) on the capsid surface, and implications for the distinction between c and e-antigens. J. Mol. Biol. 279, 1111-1121.

Depraetere, S., Verhoye, L., Leclercq, G., Leroux-Roels, G., 2001. Human $\mathrm{B}$ cell growth and differentiation in the spleen of immunodeficient mice. J. Immunol. 166, 2929-2936.

Ferrari, C., Bertoletti, A., Penna, A., Cavalli, A., Valli, A., Missale, G., Pilli, M., Fowler, P., Giuberti, T., Chisari, F.V., Fiaccadori, F., 1991. Identification of immunodominant $\mathrm{T}$ cell epitopes of the hepatitis $\mathrm{B}$ virus nucleocapsid antigen. J. Clin. Invest. 88, 214-222.

Gallina, A., Bonelli, F., Zentilin, L., Rindi, G., Muttini, M., Milanesi, G., 1989. A recombinant hepatitis B core antigen polypeptide with the protamine-like domain deleted self-assembles into capsid particles but fails to bind nucleic acids. J. Virol. 63, 4645-4652.

Gerlich, W.H., Uy, A., Lambrecht, F., Thomssen, R., 1986. Cutoff levels of immunoglobulin $\mathrm{M}$ antibody against viral core antigen for differentiation of acute, chronic and past hepatitis B virus infections. J. Clin. Microbiol. 24, 288-293.

Hemmi, H., Takeuchi, O., Kawai, T., Kaisho, T., Sato, S., Sanjo, H., Matsumoto, M., Hoshino, K., Wagner, H., Takeda, K., Akira, S., 2000. A Toll-like receptor recognizes bacterial DNA. Nature 408, 740745.

Huang, H.L., Jeng, K.S., Hu, C.P., Tsai, C.H., Lo, S.J., Chang, C., 2000. Identification and characterization of a structural protein of hepatitis $B$ virus: a polymerase and surface fusion protein encoded by a spliced RNA. Virology 275, 398-410.

Jung, M.C., Diepolder, H.M., Spengler, U., Wierenga, E.A., Zachoval, R., Hoffmann, R.M., Eichenlaub, D., Frosner, G., Will, H., Pape, G.R., 1995. Activation of a heterogeneous hepatitis B (HB) core and e antigen-specific CD4+ T-cell population during seroconversion to anti-HBe and anti-HBs in hepatitis B virus infection. J. Virol. 69, 3358-3368.

Koike, K., Iino, S., Kurai, K., Mitamura, K., Endo, Y., Oka, H., 1987. $\mathrm{IgM}$ anti-HBc in anti-HBe positive chronic type B hepatitis with acute exacerbations. Hepatology 7, 573-576.

Lazdina, U., Cao, T., Steinberg, J., Alheim, M., Pumpens, P., Peterson, D.L., Milich, D.R., Leroux-Roels, G., Sallberg, M., 2001. Molecular basis for the interaction of the hepatitis B core antigen with the surface IgG receptor on naïve B cells. J. Virol. 75, 6367-6374.

Lazdina, U., Alheim, M., Nystrom, J., Hultgren, C., Borisova, G., Sominskaya, I., Pumpens, P., Peterson, D.L., Milich, D.R., Sallberg, M., 2003. Priming of cytotoxic $T$ cell responses to exogenous hepatitis B virus core antigen is B cell dependent. J. Gen. Virol. 84, 139-146.

Machida, A., Ohnuma, H., Tsuda, F., Yoshikawa, A., Hoshi, Y., Tanaka, T., Kishimoto, S., Akahane, Y., Miyakawa, Y., Mayumi, M., 1991. Phosphorylation in the carboxy-terminal domain of the capsid protein of hepatitis B virus: evaluation with a monoclonal antibody. J. Virol. 65, 6024-6030.

Marinos, G., Smith, H.M., Naoumov, N.V., Williams, R., 1994. Quantitative assessment of serum IgM anti-HBc in the natural course and during interferon treatment of chronic hepatitis B virus infection. Hepatology 19, 303-311.

Matsumoto, M., Kikkawa, S., Kohase, M., Miyake, K., Seya, T., 2002. Establishment of a monoclonal antibody against human Toll-like recep- tor 3 that blocks double-stranded RNA-mediated signaling. Biochem. Biophys. Res. Commun. 293, 1364-1369.

Milich, D.R., McLachlan, A., 1986. The nucleocapsid of hepatitis B virus is both a T-cell-independent and a T-cell-independent antigen. Science 234, 1398-1404.

Milich, D.R., McLachlan, A., Moriarty, A., Thornton, G.B., 1987. Immune response to hepatitis $B$ virus core antigen $(\mathrm{HBcAg})$ : localization of $\mathrm{T}$ cell recognition sites within $\mathrm{HBcAg} / \mathrm{HBeAg}$. J. Immunol. 139, 12231231.

Milich, D.R., McLachlan, A., Stahl, S., Wingfield, P., Thornton, G.B., Hughes, J.L., Jones, J.E., 1988. Comparative immunogenicity of hepatitis B virus core and E antigens. J. Immunol. 141, 3617-3624.

Milich, D.R., Jones, J.E., Hughes, J.L., Price, J., Raney, A.K., McLachlan, A., 1990. Is a function of the secreted hepatitis B e antigen to induce immunologic tolerance in utero? Proc. Natl. Acad. Sci. U.S.A. 87, 6599-6603.

Milich, D.R., Schodel, F., Hughes, J.L., Jones, J.E., Peterson, D.L., 1997a. The hepatitis B virus core and e antigens elicit different Th cell subsets: antigen structure can affect Th cell phenotype. J. Virol. 71, 2192-2201.

Milich, D.R., Chen, M., Schodel, F., Peterson, D.L., Jones, J.E., Hughes, J.L., 1997b. Role of B cells in antigen presentation of the hepatitis B core. Proc. Natl. Acad. Sci. U.S.A. 94, 14648-14653.

Missale, G., Redeker, A., Person, J., Fowler, P., Guilhot, S., Schlicht, H.J., Ferrari, C., Chisari, F.V., 1993. HLA-A31- and HLA-Aw68-restricted cytotoxic $\mathrm{T}$ cell responses to a single hepatitis $\mathrm{B}$ virus nucleocapsid epitope during acute viral hepatitis. J. Exp. Med. 177, 751-762.

Mosier, D.E., 1991. Adoptive transfer of human lymphoid cells to severely immunodeficient mice: models for normal human immune function, autoimmunity, lymphomagenesis, and AIDS. Adv. Immunol. 50, 303325.

Nassal, M., 1992. The arginine-rich domain of the hepatitis B virus core protein is required for pregenome encapsidation and productive viral positive-strand DNA synthesis but not for virus assembly. J. Virol. 66, 4107-4116.

Nassal, M., Rieger, A., Steinau, O., 1992. Topological analysis of the hepatitis B virus core particle by cysteine-cysteine cross-linking. J. Mol. Biol. 225, 1013-1025.

Petit, M.A., Pillot, J., 1985. HBc and HBe antigenicity and DNA-binding activity of major core protein P22 in hepatitis B virus core particles isolated from the cytoplasm of human liver cells. J. Virol. 53, 543-551.

Pushko, P., Sallberg, M., Borisova, G., Ruden, U., Bichko, V., Wahren, B., Pumpens, P., Magnius, L., 1994. Identification of hepatitis B virus core protein regions exposed or internalized at the surface of $\mathrm{HBcAg}$ particles by scanning with monoclonal antibodies. Virology 202, 912920.

Riedl, P., Stober, D., Oehninger, C., Melber, K., Reimann, J., Schirmbeck, R., 2002. Priming Th1 immunity to viral core particles is facilitated by trace amounts of RNA bound to its arginine-rich domain. J. Immunol. 168, 4951-4959.

Salfeld, J., Pfaff, E., Noah, M., Schaller, H., 1989. Antigenic determinants and functional domains in core antigen and e antigen from hepatitis B virus. J. Virol. 63, 798-808.

Seeger, C., Mason, W.S., 2000. Hepatitis B virus biology. Microbiol. Mol. Biol. Rev. 64, 51-68.

Sjogren, M., Hoofnagle, J.H., 1985. Immunoglobulin M antibody to hepatitis B core antigen in patients with chronic type B hepatitis. Gastroenterology $89,252-258$.

Smith, H.M., Lau, J.Y., Davies, S.E., Daniels, H.M., Alexander, G.J., Williams, R., 1992. Significance of serum IgM anti-HBc in chronic hepatitis B virus infection. J. Med. Virol. 36, 16-20.

Soussan, P., Garreau, F., Zylberberg, H., Ferray, C., Brechot, C., Kremsdorf, D., 2000. In vivo expression of a new hepatitis B virus protein encoded by a spliced RNA. J. Clin. Invest. 105, 55-60.

Staib, F., Hussain, S.P., Hofseth, L.J., Wang, X.W., Harris, C.C., 2003. TP53 and liver carcinogenesis. Hum. Mutat. 21, 201-216.

Standring, D.N., Ou, J.H., Masiarz, F.R., Rutter, W.J., 1988. A signal peptide encoded within the precore region of hepatitis B virus directs 
the secretion of a heterogeneous population of e antigens in Xenopus oocytes. Proc. Natl. Acad. Sci. U.S.A. 85, 8405-8409.

Surrenti, C., Ambu, S., Patussi, V., Milani, S., Casini, A., Zacchi, P., Ceccatelli, P., Cefaratti, C., D'Agata, A., 1986. Diagnostic significance of anti-HBc IgM (RIA) in healthy HBsAg carriers and in chronic hepatitis B. J. Med. Virol. 18, 229-234.

Takahashi, K., Machida, A., Funatsu, G., Nomura, M., Usuda, S., Aoyagi, S., Tachibana, K., Miyamoto, H., Imai, M., Nakamura, T., Miyakawa, Y., Mayumi, M., 1983. Immunochemical structure of hepatitis B e antigen in the serum. J. Immunol. 130, 2903-2907.

Tary-Lehmann, M., Saxon, A., Lehmann, P.V., 1995. The human immune system in huPBL-SCID mice. Immunol. Today 16, 529-533.

Tsai, S.L., Chen, M.H., Yeh, C.T., Chu, C.M., Lin, A.N., Chiou, F.H., Chang, T.H., Liaw, Y.F., 1996. Purification and characterization of a naturally processed hepatitis $\mathrm{B}$ virus peptide recognized by CD8+ cytotoxic T lymphocytes. J. Clin. Invest. 97, 577-584.
Vanlandschoot, P., Leroux-Roels, G., 2003. Viral apoptotic mimicry: an immune evasion strategy developed by the hepatitis B virus? Trends Immunol. 24, 144-147.

Wingfield, P.T., Stahl, S.J., Williams, R.W., Steven, A.C., 1995. Hepatitis core antigen produced in Escherichia coli: subunit composition, conformational analysis, and in vitro capsid assembly. Biochemistry 34, 4919-4932.

Wynne, S.A., Crowther, R.A., Leslie, A.G., 1999. The crystal structure of the human hepatitis B virus capsid. Mol. Cell 3, 771-780.

Yi, A.K., Tuetken, R., Redford, T., Waldschmidt, M., Kirsch, J., Krieg, A.M., 1998. CpG motifs in bacterial DNA activate leukocytes through the $\mathrm{pH}$-dependent generation of reactive oxygen species. J. Immunol. 160, 4755-4761.

Zheng, J., Schodel, F., Peterson, D.L., 1992. The structure of hepadnaviral core antigens. Identification of free thiols and determination of the disulfide bonding pattern. J. Biol. Chem. 267, 9422-9429. 